\title{
Mechanical characteristics of swollen elastomers under cyclic loading
}

\author{
A.B. Chai ${ }^{\text {a }}$, A. Andriyana ${ }^{\mathrm{a}, *}$, E. Verron $^{\mathrm{b}}$, M.R. Johan ${ }^{\mathrm{a}}$ \\ ${ }^{a}$ Department of Mechanical Engineering, University of Malaya, 50603 Kuala Lumpur, Malaysia \\ ${ }^{\mathrm{b}}$ Institut de Recherche en Génie Civil Mécanique (GeM) - UMR CNRS 6183, École Centrale de Nantes, BP 92101, 44321 Nantes, France
}

\begin{abstract}
The environmental and economic concerns have raised the popularity of biodiesel as a potential replacement for conventional fuel. However, the incompatibility of engineering rubber components with biodiesel affects significantly the performance of the components. Majority of the compatibility studies focus on evaluating the degradation of mechanical properties of the rubbers due to contamination of different types of biodiesel. Nevertheless, the resulting mechanical responses of swollen rubbers, in particularly under cyclic and fatigue loading conditions, are rarely investigated. In engineering applications where elastomeric components are concurrently subjected to fluctuating mechanical loading and contamination of hostile liquids such as biodiesel, it is crucial to investigate the mechanical responses of these components for durability analysis. In this view, the present study aims to investigate the effect of swelling, due to biodiesel diffusion in the elastomers, on the macroscopic mechanical responses under cyclic loading conditions. Simple stress-free immersion tests are conducted on elastomers and the resulting mechanical responses are evaluated. The focus of the present work is on the effect of biodiesel diffusion on the inelastic responses classically observed in elastomers under cyclic loading conditions, i.e. stress-softening, hysteresis and stress relaxation. The results show that the above inelastic responses decrease significantly when the swelling level increases.
\end{abstract}

\section{Introduction}

The recent oil crisis and dramatic increase in conventional fuel price have motivated the world to search for alternative fuels. One of the feasible solutions is the use of biodiesel derived from vegetable oil and animal fat. The biodiesel has been proven to be environmental friendly and provides properties similar to that of conventional fuel. However, the biodiesel has different composition from conventional diesel. Indeed, while biodiesel consists of a mixture of fatty acid ester, conventional fuel consists of a mixture of hydrocarbon [1]. This change of composition leads to difficulties in terms of material compatibility especially in industrial applications involving elastomeric materials.

The compatibility studies of several types of elastomers in diesel and palm biodiesel have been conducted [1-3]. In these works, only physical degradations related to the swelling, hardness and tensile strength of materials were studied. Trakarnpruk and Porntangjitlikit [3] evaluated compatibility of elastomers in B10 (blend of $10 \%$ of palm biodiesel and $90 \%$ of conventional diesel) after immersion of 22,670 , and $1008 \mathrm{~h}$ at $100^{\circ} \mathrm{C}$. Six types of elastomers were investigated: NBR, Hydrogenated Nitrile Butadiene Rubber (HNBR), NBR/Polyvinyl Chloride (PVC), acrylic rubber,

\footnotetext{
* Corresponding author. Tel.: +60 37967 5254; fax: +60 379675317.

E-mail address: andri.andriyana@um.edu.my (A. Andriyana).
}

co-polymer Fluorocarbon (FKM), and terpolymer FKM. The authors found that the mechanical properties of NBR, NBR/PVC and acrylic rubber were affected more than those of co-polymer Fluorocarbon (FKM) and terpolymer FKM. Similar other compatibility tests of high density polyethylene (HDPE) in soybean, sunflower biofuel [4] and bioethanol [5] were conducted using different characterization techniques such as Raman and FTIR spectroscopies, and differential scanning calorimetry. Moreover, there are collections of experimental studies on mechanical responses of polymeric gels in solvents [6-8]. It is to note that the works focusing on the effect of palm biodiesel diffusion on the macroscopic mechanical responses of the rubber components, in particularly under cyclic and fatigue loading conditions are less common [9].

Under cyclic loading, dry rubber exhibits strong inelastic responses including stress-softening and hysteresis. The stress-softening corresponds to the decrease of stress level in the uploading during the first couples of loading cycles. This phenomenon, firstly observed by Bouasse and Carriére [10] then intensively studied by Mullins [11], is often referred to as the Mullins effect. Up to this date, there is no unanimous microscopic explanation for the stress-softening $[12,13]$. The hysteresis corresponds to the amount of energy loss during a cycle and can be related to either viscoelasticity [14], viscoplasticity [15] or strain-induced crystallization [16]. The hysteresis is found to stabilize after first couples of loading cycles. 
The present work can be regarded as a first step toward an integrated durability analysis of industrial rubber components exposed to hostile environments, e.g. oil environment in biofuel systems, during their service. More precisely, the effect of swelling, due to diffusion of palm biodiesel into rubber, on the macroscopic mechanical responses under cyclic loading condition is investigated. Two types of rubber are considered: Nitrile Butadiene Rubber (NBR) and Polychloroprene Rubber (CR).

In Section 2, the experimental procedures are detailed. The experimental results are summarized and discussed in Section 3. Concluding remarks are given in Section 4.

\section{Experimental program}

\subsection{Materials}

Commercial grade of NBR and CR with 60 shore hardness $A \pm 5$ used in this research were provided by MAKA Engineering Sdn. Bhd., Malaysia. The NBR and CR have specific gravity of $1.4 \pm 0.1$ and $25 \mathrm{wt} . \%$ of carbon black. Due to confidentiality constraint, the detailed compound ingredients are not provided here. For each type of rubber compounds, the vulcanization process was performed by compression molding process at $165^{\circ} \mathrm{C}$ for 5 min under a pressure of approximately $6.89 \mathrm{MPa}$ from an electrical resistance heating press. The rubber specimens for swelling and mechanical tests are annular cylindrical block with outside diameter of $50 \mathrm{~mm}$, inner diameter of $38 \mathrm{~mm}$ and height of $10 \mathrm{~mm}$. Note that no standard is followed in the determination of specimen geometry. Indeed, the wall thickness of the specimen is chosen such that swelling in the specimen during the immersion test can occur in a relatively short period of time while ensuring that specimen buckling will not occur during the compression test.

The palm biodiesel (B100) was purchased from Am Biofuels Sdn. Bhd., Malaysia. Table 1 shows the analysis report of the palm biodiesel used in the present study.

\subsection{Swelling measurement}

The weight of dry specimens was measured in the air and in the distilled water before the swelling test. After weight measurement, the specimens were hanged and immersed in the biodiesel bath at room temperature for various immersion durations: 2, 5, 10, 20 and 30 days. Each specimen was completely immersed in palm biodiesel as shown in Fig. 1, thereby allowing stress-free swelling to occur in the rubber specimens. When the samples reached the desired immersion duration, they were removed from the container and dipped quickly into acetone to remove the oil excess. The samples were then wiped with filter paper and the weight of swollen rubber specimens in the air and in the distilled water were

Table 1

Properties of B100 palm biodiesel.

\begin{tabular}{llll}
\hline Test & Unit & Methods & Results \\
\hline Ester content & $\%(\mathrm{~m} / \mathrm{m})$ & EN 14103 & 96.9 \\
Density at $15{ }^{\circ} \mathrm{C}$ & $\mathrm{kg} / \mathrm{m}^{3}$ & EN ISO 12185 & 875.9 \\
Viscosity at $40{ }^{\circ} \mathrm{C}$ & $\mathrm{mm}^{2} / \mathrm{s}$ & EN ISO 3104 & 4.667 \\
Flash point & ${ }^{\circ} \mathrm{C}$ & EN ISO 3679 & 168 \\
Cetane number & - & EN ISO 5165 & 69.7 \\
Water content & $\mathrm{mg} / \mathrm{kg}$ & EN ISO 12937 & 155 \\
Acid value & $\mathrm{mgKOH} / \mathrm{g}$ & EN ISO 3679 & 0.38 \\
Methanol content & $\%(\mathrm{~m} / \mathrm{m})$ & EN 14110 & $<0.01$ \\
Monoglyceride content & $\%(\mathrm{~m} / \mathrm{m})$ & EN 14105 & 0.67 \\
Diglyceride content & $\%(\mathrm{~m} / \mathrm{m})$ & EN 14105 & 0.2 \\
Triglyceride content & $\%(\mathrm{~m} / \mathrm{m})$ & EN 14105 & 0.2 \\
Total glycerine & $\%(\mathrm{~m} / \mathrm{m})$ & EN 14105 & 0.25 \\
\hline
\end{tabular}

measured immediately. The percentage of mass change and volume change were calculated using the following relations [3]:

$\%$ Mass change $=\frac{M_{2}-M_{1}}{M_{1}} \times 100$

$\%$ Volume change $=\frac{\left(M_{2}-M_{4}\right)-\left(M_{1}-M_{3}\right)}{\left(M_{1}-M_{3}\right)} \times 100$

where $M_{1}$ and $M_{2}$ are the mass in air before and after immersion respectively while $M_{3}$ and $M_{4}$ are the mass in water before and after immersion respectively. For each immersion duration, the average results were calculated from four test specimens.

\subsection{Mechanical testing}

To gain insight on the effect of swelling, due to biodiesel diffusion, on the mechanical response of elastomers, uniaxial cyclic compressive tests on dry and swollen rubber specimens were carried out using Instron testing machine operated at room temperature. Circular compression plates were attached to the machine in order to ensure uniform displacement control on the specimens. The experimental setup was connected to a computer to record the experimental data. The tests were conducted at a constant displacement rate of $0.1 \mathrm{~mm} / \mathrm{s}$ to avoid excessive increase in the temperature of the specimens, i.e. thermal effect is not considered in the present study. Two types of mechanical tests were conducted:

(1) Cyclic compressive test. The specimen was subjected to cyclic compressive loading at $40 \%$ maximum compressive strains of 6 cycles each.

(2) Multi-relaxation test. After experiencing 6 cycles of compressive loading, the specimen was subjected to relaxation tests at different strain levels during uploading and unloading.

To ensure repeatability of the results, at least three specimens were used in each test.

\section{Results and discussion}

\subsection{Swelling}

The variation of mass change and volume change of NBR and CR as a function of immersion duration is shown in Fig. 2. It can be seen that these plots show similar patterns. The swelling in both NBR and CR increases when the exposure time (immersion duration) is increased from 2 days to 30 days. The palm biodiesel uptake is relatively fast at the initial stage due to its great affinity for oil uptake [17]. The rate of swelling, either expressed in terms of mass change or volume change, appears to be high at short exposure time before decreasing at longer exposure time. Accelerated swelling is initiated with absorption of liquids when the liquids dissolve on the surface layer of the rubber (adsorption) until certain concentration. Subsequently, the liquids penetrate slowly into the rubber by diffusion until the rubber specimen achieves equilibrium swelling [18].

$\mathrm{CR}$ is made from emulsion polymerization of 2-chloro-1, 3butadiene and NBR is emulsion copolymer of acrylonitrile and butadiene [19]. The polar substituent of acrylonitrile in NBR and chlorine substituent in CR contribute to their resistance to mineral oils [2]. However, the tendency of rubber to swell in solvent generally follows the principle of "like dissolve like": polar solvent are more likely to dissolve polar substances and non-polar substances are more likely to dissolve in non-polar solvent [20]. The high polarity of ester in palm biodiesel favors the forming of 
a

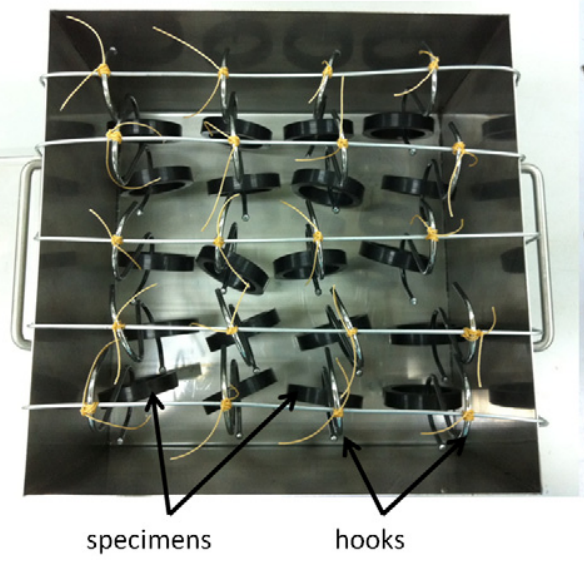

b

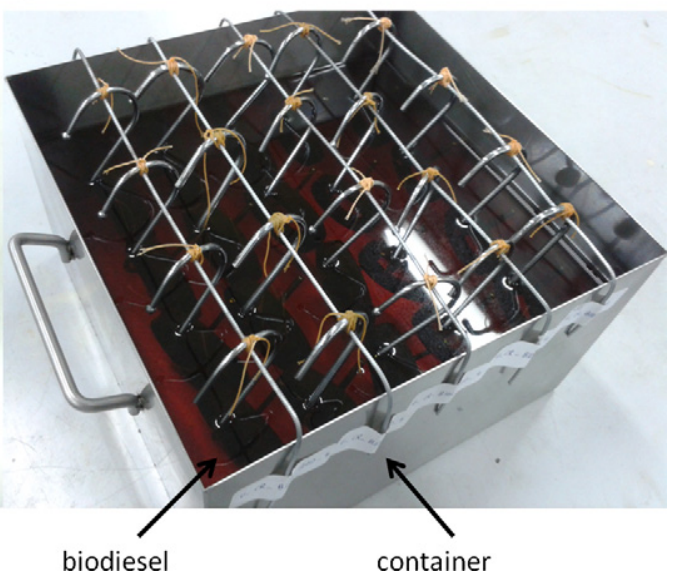

Fig. 1. Free swelling test for the specimens (a) before immersion and (b) after immersed in B100.
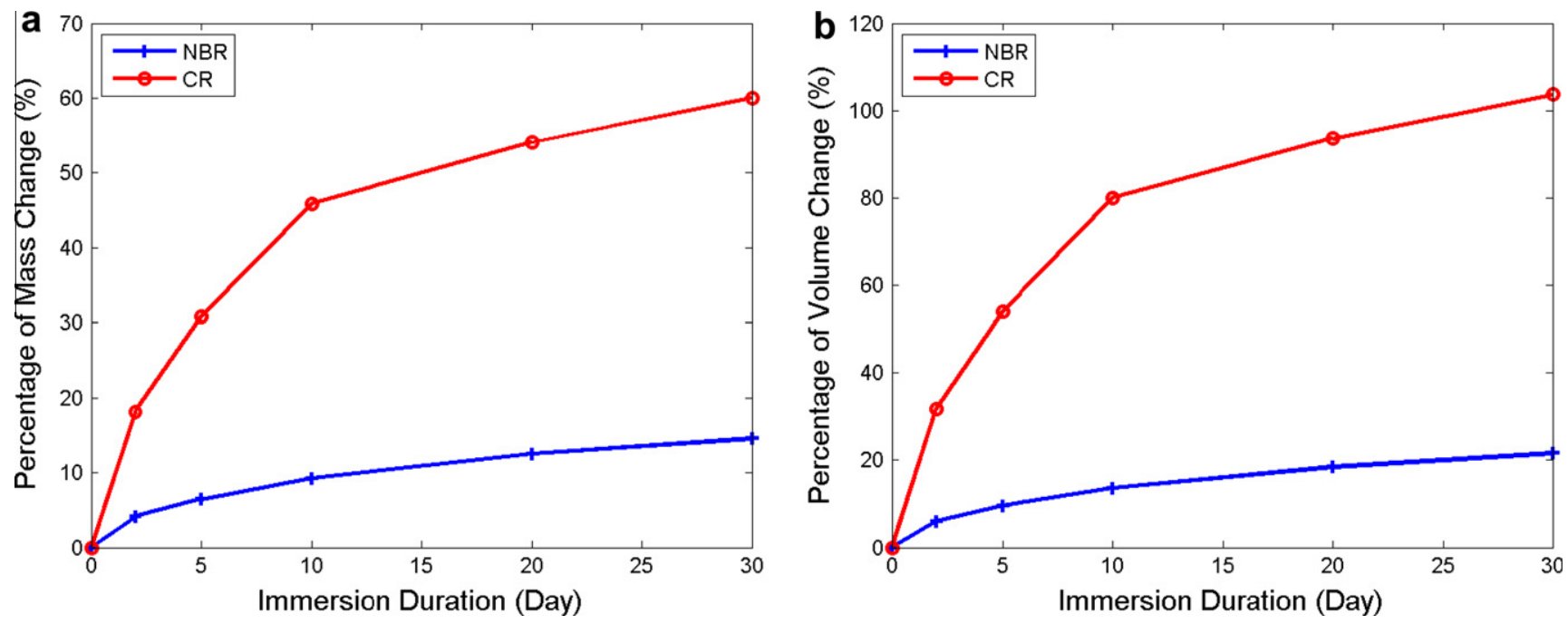

Fig. 2. (a) Mass change and (b) volume change exhibited by NBR and CR after immersion in palm biodiesel at different immersion durations.

polymer-solvent interaction in CR and high polarity NBR [2,21]. Therefore, for engineering applications involving the contamination of highly polar solvent such as palm biodiesel in highly polar elastomeric components (e.g. CR and high polarity NBR), caution should be taken so that the resulting swelling does not significantly decrease the performance of the component during the service.

\subsection{Influence of swelling on macroscopic mechanical response}

The stress-strain response of dry and swollen rubbers under cyclic compressive loading is presented in Fig. 3. Generally, it is observed that the natures of stress-strain curves are preserved. However, for a given strain, lower stresses are recorded for swollen rubbers. Swollen CR shows lower stress level than swollen NBR. Significant decrease of stress in CR can be related to high swelling level due to strong interaction of rubber-solvent matrix system [22]. Both dry and swollen rubbers exhibit inelastic responses such as stress-softening and hysteresis. The stress-softening disappears after around five loading cycles while the hysteresis stabilizes after five loading cycles. Moreover, it is to note that for both NBR and CR, the inelastic responses appear to be significantly smaller in the case of swollen rubbers.
To highlight the effect of swelling level resulting from different immersion durations, the mechanical response of NBR and CR specimens during the first cyclic loading is depicted in Fig. 4. In this figure, the stress is defined with respect to the swollen-unstrained configuration (initial swollen cross section). For each material, stress-strain curves of dry rubber and swollen rubbers (correspond to 5,10, 20 and 30 days immersion durations) are presented. The figures suggest that generally, the inelastic responses in both NBR and CR, i.e. hysteresis and stress-softening, appears to be smaller when the swelling level is higher. In the next subsections, further discussions on the stress-softening, hysteresis and stress relaxation are presented.

\subsection{Stress-softening}

It was observed that swollen elastomers exhibit stress-softening which disappears after around 5 cycles of loading (see Fig. 3). In the following, only stress-softening occurred between the first uploading and second uploading is considered.

Before proceeding further with the evolution of stress-softening in swollen rubbers under cyclic loading, it is important to recall the difference between the stress decrease associated with the decrease in strength of rubber and the one associated with the 

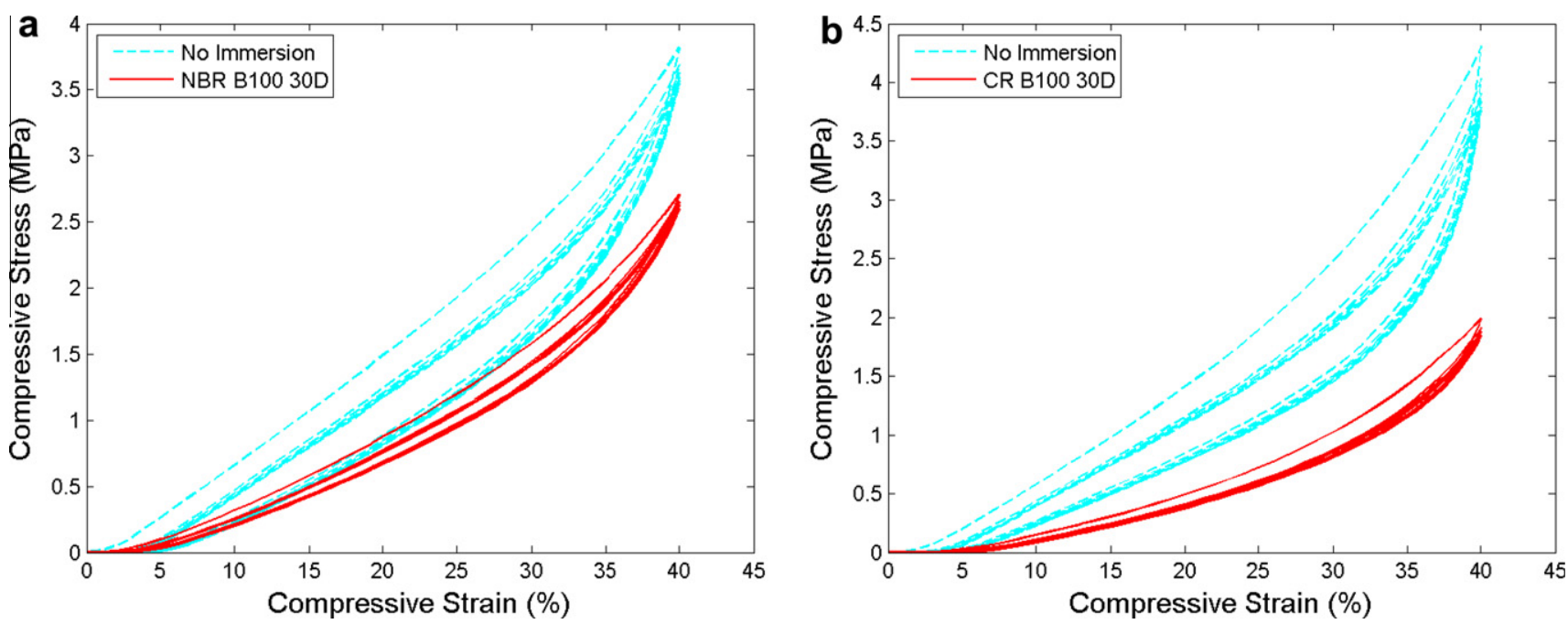

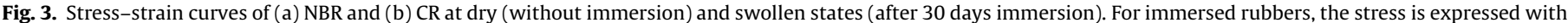
respect to the unswollen-unstrained configuration (initial dry cross section).
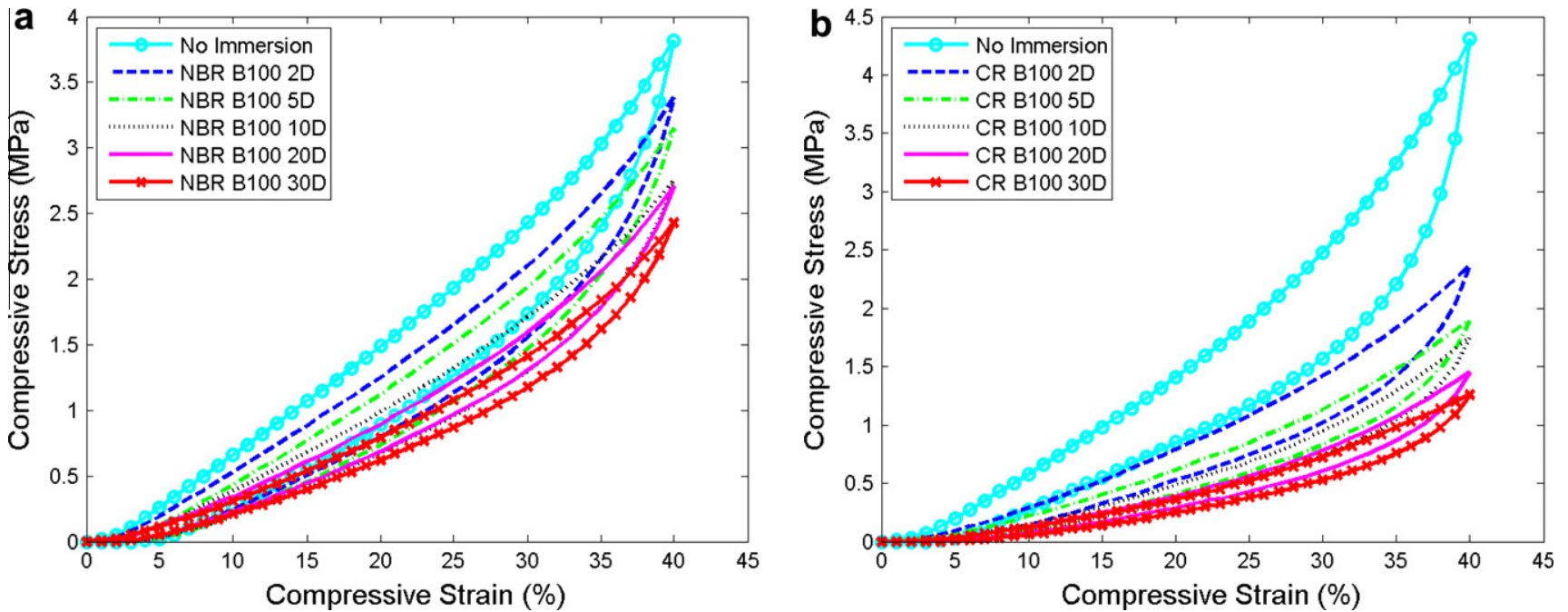

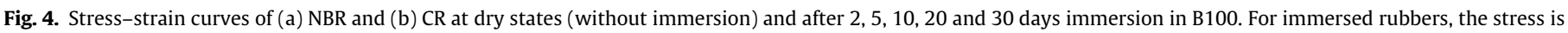
expressed with respect to the swollen-unstrained configuration (initial swollen cross section).

stress-softening. In the former, the idea is to compare the stress level during the first uploading between dry rubber and swollen rubber. The latter compares the stress level during the first uploading and the second uploading in one rubber (either dry or swollen). To characterize the former and the latter, we use the terms stress drop and stress-softening respectively defined by (see Fig. 5):

Stress drop $=\frac{P_{d_{1}}^{u p}-P_{s_{1}}^{u p}}{P_{d_{1}}^{u p}}$

Stress softening $($ dry $)=\frac{P_{d_{1}}^{u p}-P_{d_{2}}^{u p}}{P_{d_{1}}^{u p}}$

Stress softening $($ swollen $)=\frac{P_{s_{1}}^{u p}-P_{s_{2}}^{u p}}{P_{s_{1}}^{u p}}$

where $P_{d_{1}}^{u p}$ is the stress in dry rubber during uploading of the first cycle, $P_{d_{3}}^{u p}$ is the stress in dry rubber during uploading of the second cycle $P_{s_{1}}^{u p}$ is the stress in swollen rubber during uploading of the first cycle and $P_{s_{2}}^{u p}$ is the stress in swollen rubber during uploading of

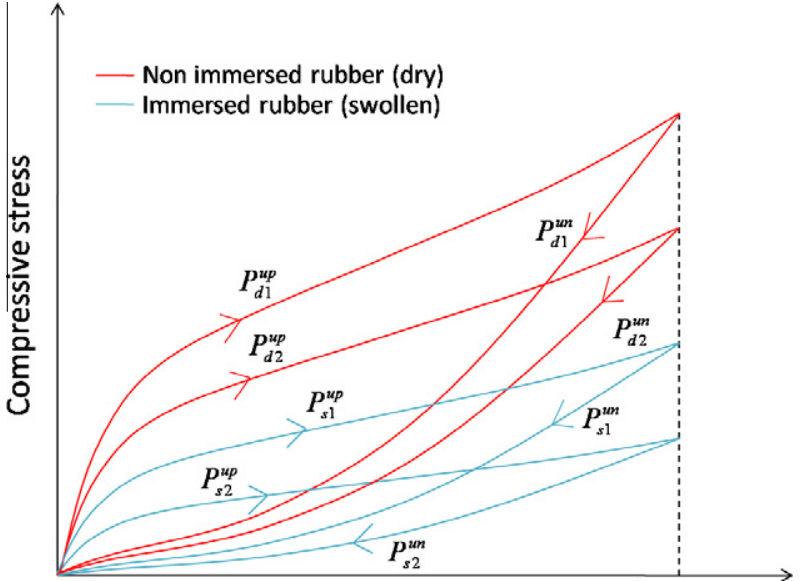

Compressive strain

Fig. 5. Illustration of two first cycles stress-strain curve of previously nonimmersed (dry) and immersed (swollen) rubbers under cyclic loading. 

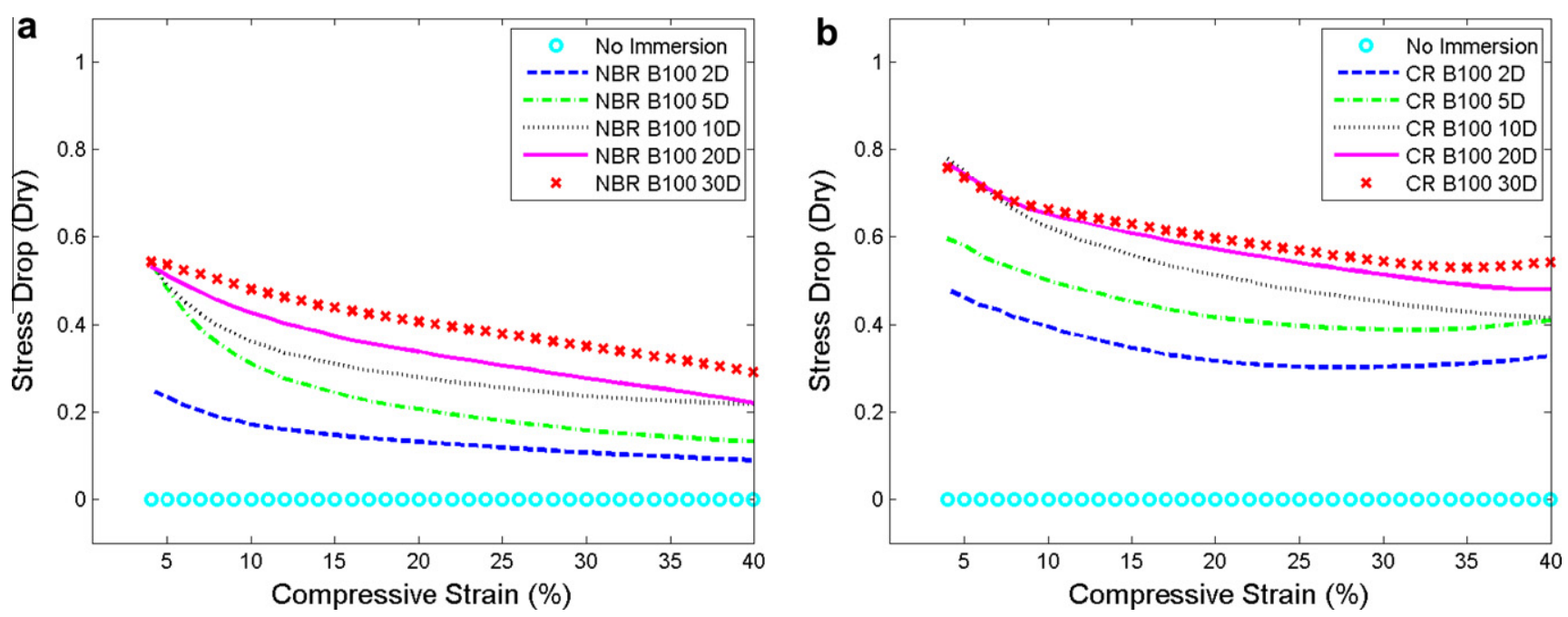

Fig. 6. Stress drop in (a) NBR and (b) CR previously immersed in B100. Results correspond to 2, 5, 10, 20 and 30 days of immersion duration.
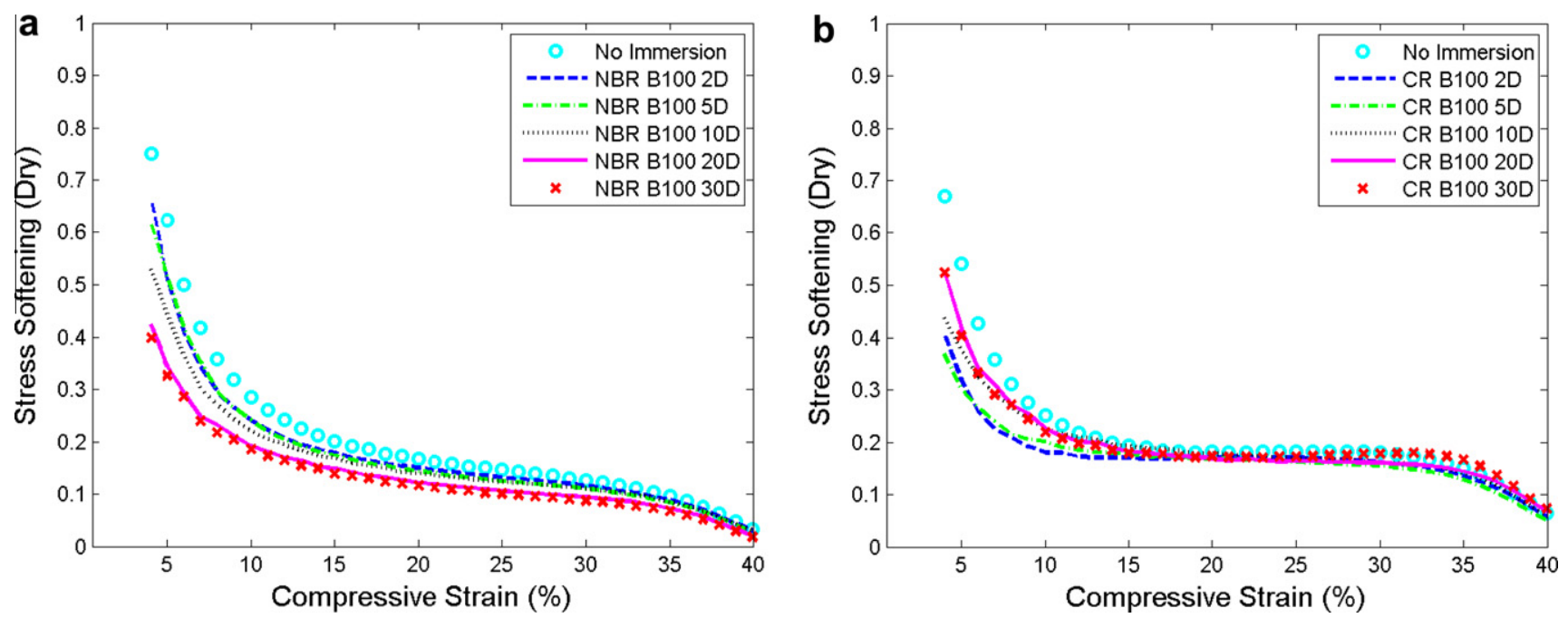

Fig. 7. Stress-softening in (a) NBR and (b) CR previously immersed in B100. Results correspond to 2, 5, 10, 20 and 30 days of immersion duration.

the second cycle. In the next paragraph, the effect of swelling on the evolution of stress drop and stress-softening is discussed.

Remark 1. It is important to remember that for swollen rubbers, the stresses $P_{s_{1}}^{u p}$ and $P_{s_{2}}^{u p}$ have to be expressed with respect to the unswollen-unstrained configuration, i.e. initial dry cross section of the specimen.

The stress drop exhibited by NBR and CR is shown in Fig. 6. Note that, the stress drop in dry (non-immersed) rubbers is zero by definition. As depicted in this figure, both NBR and CR experience stress drop in the presence of biodiesels. The stress drop appears to decrease linearly with the applied compressive strain in the range of $10-40 \%$ and $5-40 \%$ for NBR and CR respectively. For given immersion duration, stress drop in CR is higher than that in NBR. As underlined by George et al. [22], the high level of swelling experienced by $\mathrm{CR}$ as shown in Fig. 2 appears to contribute significantly to the decrease of its strength.

Concerning the stress-softening, it is observed that the stresssoftening decreases as the strain level approaches the maximum strain previously endured by the material as classically observed in rubber under cyclic loading conditions [12]. Unlike the stress drop, an opposite trend is found in stress-softening, i.e. the

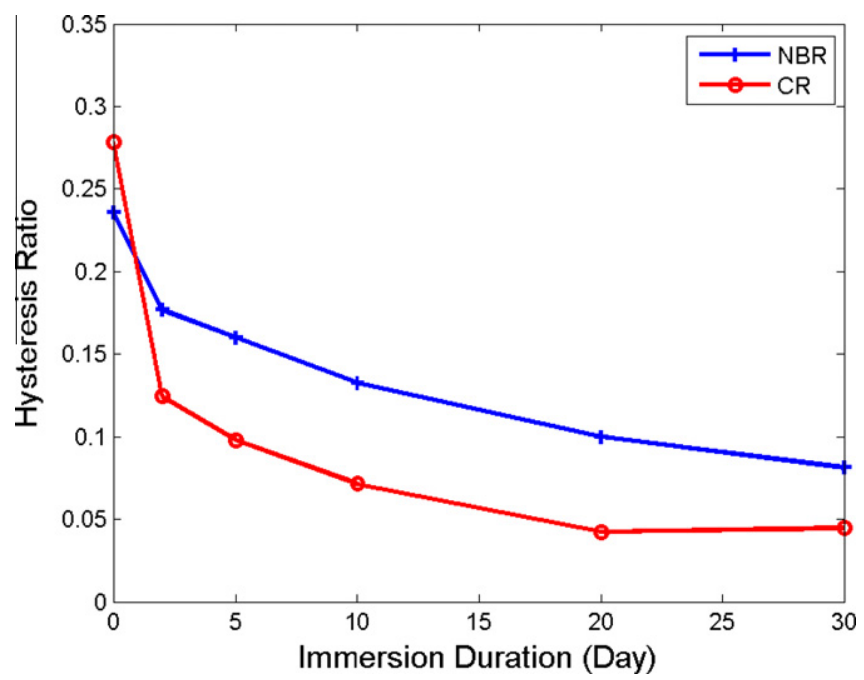

Fig. 8. Hysteresis ratio in NBR and CR under cyclic compressive loading at $40 \%$ maximum strain. Results correspond to 2, 5, 10, 20 and 30 days of immersion duration. 


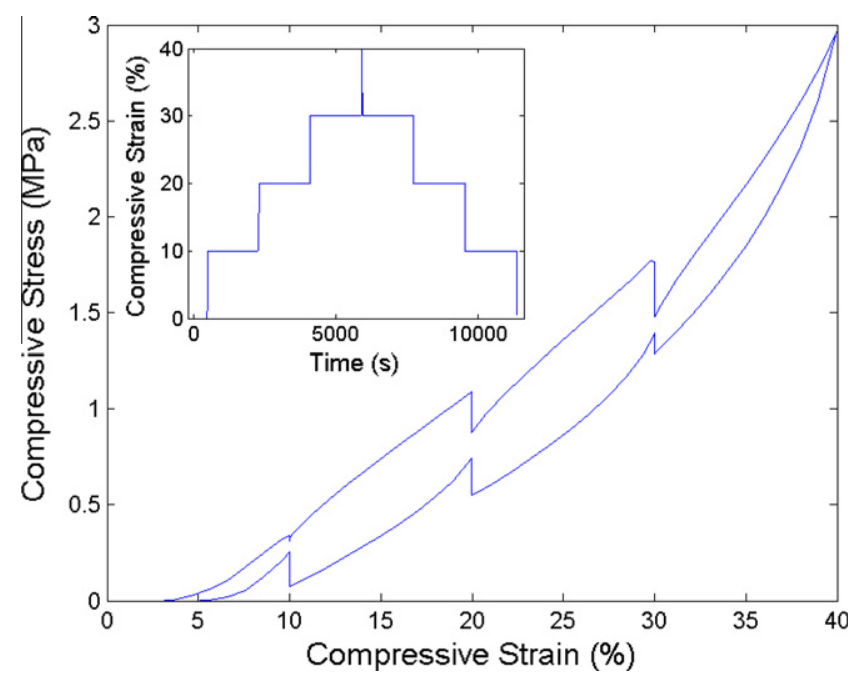

Fig. 9. Engineering stress-strain response of dry NBR under multi step relaxation test at $0.1 \mathrm{~mm} / \mathrm{s}$ displacement rate.

presence of liquids (swelling) decreases the stress-softening as can be consulted in Fig. 7. While in the case of NBR this trend is easily observed, in the case of CR it is less noticeable. Indeed, for relatively low compressive strains, i.e. below $15 \%$ strains, discrepancies are found in CR previously immersed during 10, 20 and 30 days: the level of stress softening for these three immersion durations is close to the one of dry rubber. While the exact reason of these discrepancies is not known, it could be attributed to the fact that at low compressive strain and high swelling level, the measured stress is so small that the corresponding level of stress-softening cannot be correctly described by Eq. $(4)_{2}$.

\subsection{Hysteresis}

The hysteresis in our materials is found to stabilize after 5 cycles of loading (see Fig. 3). In order to investigate the effect of swelling on hysteresis of elastomers, the amount of hysteresis ratio at different immersion durations is plotted in Fig. 8. Following Bergström and Boyce [14], the hysteresis loss ratio is defined as the amount of stabilized hysteresis (after 5 th cycle), $\mathrm{H}_{5}$ (given by the difference of the area under the uploading and the unloading path of the stress-strain curve) divided by the supplied energy, $E_{s}$ during uploading (given by the area under the uploading path

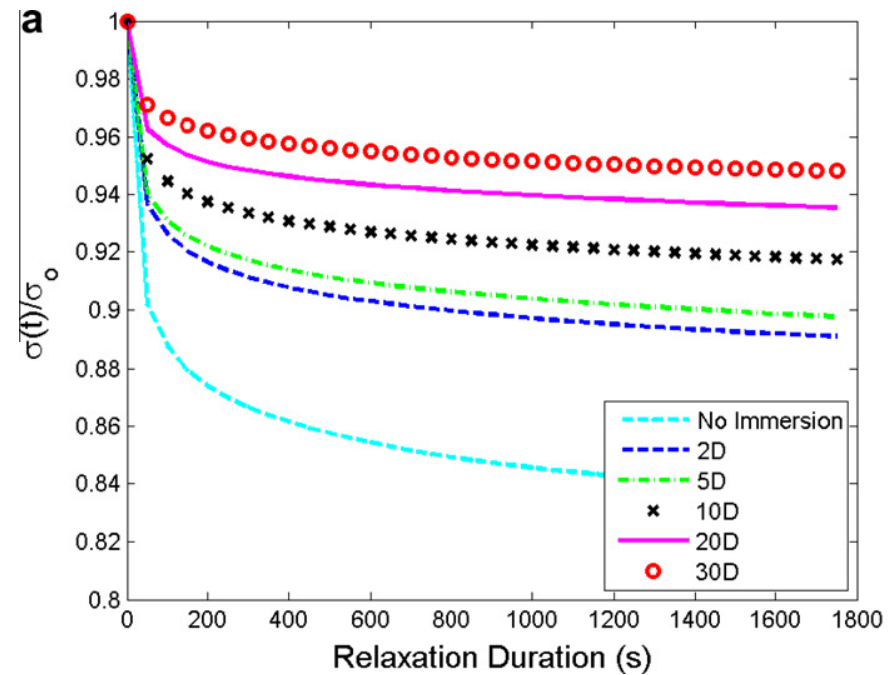

of the stress-strain curve) at the corresponding cycle as described by the following equation:

Hysteresis loss ratio $=\frac{H_{5}}{E_{s}}$

The plot clearly indicates that for both NBR and CR the hysteresis ratio decreases when the immersion duration increases, i.e. when swelling increases. Initially at dry state, CR has higher hysteresis ratio. As swelling occurs, the hysteresis ratio in CR decreases significantly and becomes consistently lower than that of NBR. Indeed, when the immersion duration is increased to 30 days, the hysteresis ratio in CR decreases by $84 \%$ from 0.278 (dry state) to 0.045 (swollen state). In the case of NBR, the hysteresis ratio decreases by $66 \%$ from 0.236 (dry state) to 0.081 (swollen state). These results highlight the decrease of viscous effect in elastomers as swelling level increases. Note that in the context of fatigue, Cho et al. [23] attributes the increase of fatigue crack growth in swollen rubbers (decrease in fatigue life) to the decrease of hysteresis.

\subsection{Stress-relaxation}

The effect of the biodiesel diffusion on the time-dependent behavior of the elastomeric materials can be probed with experiments illustrated in the inset of Fig. 9. In this experiment, after the specimen was pre-conditioned with 6 cycles of compressive loading to a maximum compressive strain level of $40 \%$, the multi-relaxation tests at strain levels of $10 \%, 20 \%$ and $30 \%$ were conducted during the uploading and unloading. Similar tests were conducted for dry elastomers by Lion [15] and Bergström and Boyce [14] among others. It is observed that the compressive stress decreases during the relaxations in the uploading and increases during the relaxations in the unloading approaching what appear to be an equilibrium state [14] as depicted in Fig. 9.

Further investigation on the stress relaxation is presented in Fig. 10 where the normalized stress is plotted as a function of relaxation duration for different immersion durations (swelling levels). In this figure, the normalized stress is defined by the ratio between the value of stress during relaxation at specific time, $\sigma(t)$ and the maximum stress achieved at the beginning of the corresponding relaxation, $\sigma_{o}$ Only stress relaxation at strain level of $30 \%$ during uploading is presented. As clearly shown, the two graphs in Fig. 10 shows similar trend. The presence of liquid (swelling) appears to render the material under loading becomes closer to the equilibrium state, i.e. the viscous (time-dependent) contribution to the macroscopic mechanical response of material

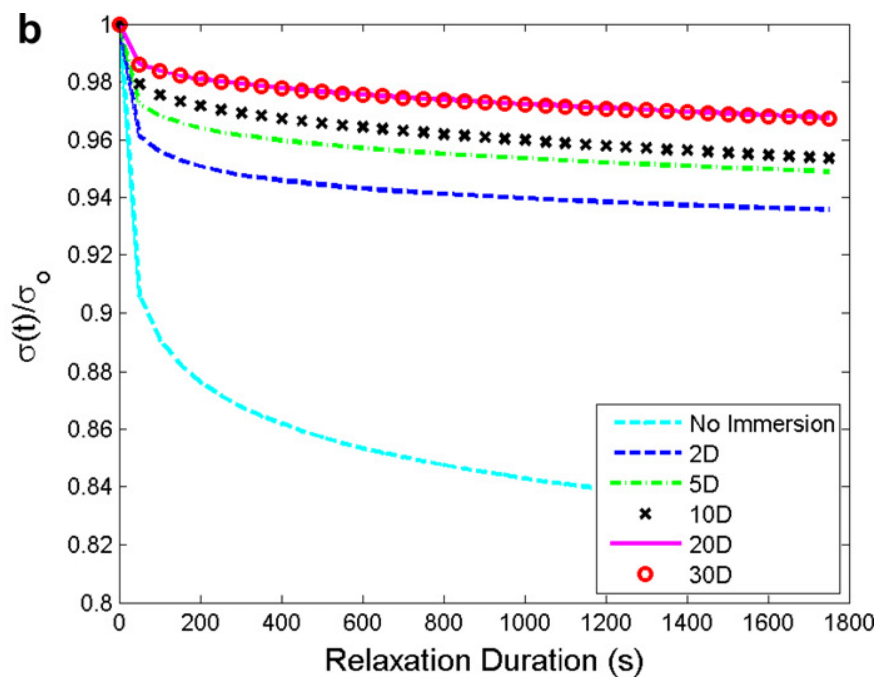

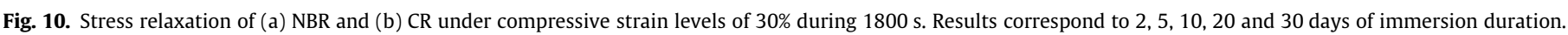


becomes smaller which is consistent with the results on the hysteresis discussed in the previous subsection. Indeed, after $1800 \mathrm{~s}$ of relaxation, the stress decreases by the amount of $16 \%$ for dry NBR and by $6 \%$ whenever the specimen is immersed in B100 for 30 days. While for $\mathrm{CR}$, the stress only decreases by $3 \%$ after immersed for 30 days whereas the stress in dry CR decreases by $17 \%$ after $1800 \mathrm{~s}$ of relaxation. As emphasized by Radhakrishnan Nair [24] and Wypych [25], the palm biodiesel appears to act as lubricant facilitating movement of the polymer chain segments.

\section{Conclusions}

In the present work, a simple experimental setup was developed to probe the mechanical responses of swollen rubbers under cyclic compressive loading conditions. Different levels of swelling resulting from different immersion durations of elastomeric specimens were considered. It was found that the rate of swelling is relatively high at short immersion durations and becomes lower at longer immersion duration. For given immersion duration, the swelling in CR was systematically higher than the one in NBR.

The diffusion of biodiesel into rubber appeared to reduce the strength of rubber. Under cyclic loading conditions, both swollen NBR and swollen CR exhibited inelastic responses, i.e. stress-softening, hysteresis and stress relaxation. However, the amount of these inelastic responses in swollen rubbers was significantly lower than that found in dry rubbers.

To close the paper, it is to note that the present works focuses only on stress-free swelling. Further investigations on the effect of multiaxial stress state on the swelling and the resulting mechanical response are needed.

\section{Acknowledgement}

The authors greatly appreciate the financial support from Ministry of Higher Education Malaysia through High Impact Research Grant HIR-MOHE D000008-16001.

\section{References}

[1] Haseeb ASMA, Masjuki HH, Siang CT, Fazal MA. Compatibility of elastomers in palm biodiesel. Renew Energy 2010;35:2356-61.
[2] Haseeb ASMA, Jun TS, Fazal MA, Masjuki HH. Degradation of physical properties of different elastomers upon exposure to palm biodiesel. Energy 2011;36:1814-9.

[3] Trakarnpruk W, Porntangjitlikit S. Palm oil biodiesel synthesized with potassium loaded calcined hydrotalcite and effect of biodiesel blend on elastomer properties. Renew Energy 2008;33:1558-63.

[4] Maru MM, Lucchese MM, Legnani C, Quirino WG, Balbo A, Aranha IB, et al Biodiesel compatibility with carbon steel and HDPE parts. Fuel Process Technol 2009;90:1175-82

[5] Berlanga-Labari C, Albistur-Goñi A, Barado-Pardo I, Gutierrez-Peinado M, Fernández-Carrasquilla J. Compatibility study of high density polyethylene with bioethanol-gasoline blends. Mater Des 2011:32:441-6.

[6] Hirotsu S. Stress relaxation and elastic moduli in the swollen and the shrunken phases of $N$-isopropylacrylamide gel. Macromolecules 2004;37:3415-24.

[7] Urayama K, Takigawa T, Masuda T. Stress relaxation and creep of polymer gels in solvent under uniaxial and biaxiai deformations. Rheol Acta 1994;33:89-98.

[8] Sasaki S. Stress relaxation of deformed gel in a good solvent. J Chem Phys 2004;120:5789-94.

[9] Chai AB, Andriyana A, Verron E, Johan MR, Haseeb ASMA. Development of a compression test device for investigating interaction between diffusion of biodiesel and large deformation in rubber. Polym Test 2011;30:867-75.

[10] Bouasse H, Carriére Z. Courbes de traction du caoutchouc vulcanisé. Ann Fac Sci Toulouse 1903;5:257-83.

[11] Mullins L. Effect of stretching on the properties of rubber. Rubber Chem Technol 1948;21:281-300.

[12] Diani J, Fayolle B, Gilormini P. A review on the Mullins effect. Eur Polym J 2009;45:601-12.

[13] Marckmann G, Verron E, Gornet L, Chagnon G, Charrier P, Fort P. A theory of network alteration for the Mullins effect. J Mech Phys Solids 2002;50:2011-28.

[14] Bergström JS, Boyce MC. Constitutive modeling of the large strain timedependent behavior of elastomers. J Mech Phys Solids 1998;46:931-54.

[15] Lion A. On the large deformation behaviour of reinforced rubber at different temperatures. J Mech Phys Solids 1997;45:1805-34.

[16] Trabelsi S, Albouy PA, Rault J. Crystallization and melting processes in vulcanized stretched natural rubber. Macromolecules 2003;36:7624-39.

[17] Mostafa A, Abouel-Kasem A, Bayoumi MR, El-Sebaie MG. Effect of carbon black loading on the swelling and compression set behavior of SBR and NBR rubber compounds. Mater Des 2009;30:1561-8.

[18] Gent AN. Engineering with rubber. How to design rubber components. Hanser: 2001.

[19] Dick JS. Rubber technology: compounding and testing for perfomance. Hanser; 2001.

[20] Zhang H, Cloud A. Research progress in calenderable fluorosilicone with excellent fuel resistance. SAMPE; 2007.

[21] Pekcan Ö, Uğur Ş. Molecular weight effect on polymer dissolution: a steady state fluorescence study. Polymer 2002;43:1937-41.

[22] George SC, knörgen M, Thomas S. Effect of nature and extent of crosslinking on swelling and mechanical behavior of styrene-butadiene rubber membranes. J Membr Sci 1999;163:1-17.

[23] Cho K, Jang WJ, Lee D, Chun H, Chang Y-W. Fatigue crack growth of elastomers in the swollen state. Polymer 2000;41:179-83.

[24] Radhakrishnan Nair N. Studies on depolymerized natural rubber. PhD thesis: Mahatma Gandhi University; 1997.

[25] Wypych G. Handbook of plassticizers. ChemTec Publishing; 2004 